\title{
The office tyrant: abuse of power through e-mail
}

\author{
C. T. Romm
}

University of Wollongong

Wollongong, NSW 2500

Australia

Tel: (042)214043, Fax: (042)27278,E-Mail: c.romm@uow.edu.au

\author{
Nava Pliskin \\ Ben Gurion University \\ Beer-Sheva \\ Israel
}

\begin{abstract}
The changing role of technology in the modern office has been accompanied by a proliferation of research activity focusing initially on the technical aspects and more recently on the social and political aspects of the diffusion process, including power and politics. This paper builds on the work of Markus on power and politics in IT, extending it to e-mail and more specifically, to the use of email for petty tyranny. We start with a review of the literature on petty tyranny and its implications to Information Technologies and e-mail. The review is concluded with a series of assertions about the use of e-mail for petty tyranny. To demonstrate how these assertions can operate within an organisational context, a case study is presented. In the case, e-mail was used by a department head to manipulate, control, and coerce employees. The discussion synthesises the analysis by demonstrating that e-mail features made it amenable to political abusive tyrannical uses. The paper is concluded with a discussion of the implications from this case to e-mail research and practice.
\end{abstract}

\section{Keywords}

E-mail, Power and Politics, abuse of technology in organisational settings 


\section{INTRODUCTION}

The last decades have witnessed an exponential increase in the diffusion of office technologies. The new technologies, particularly e-mail, have redefined the nature of office work, making differenttime/different-place/different-culture teams the norm in many organisations. The changing role of technology in the modern office has been accompanied by a proliferation of research activity focusing initially on the technical aspects (Culnan, and Markus, 1987; Eveland and Bikson, 1988; Pliskin, Ball, and Curley, 1989; Pliskin, 1989; Pliskin and Romm, 1990) and more recently on the social and political aspects of the diffusion process (Pliskin, Romm, Lee, and Weber, 1993; Romm, Pliskin, Weber, and Lee, 1991; Markus, 1994).

One of the more intriguing lines of research on diffusion and implementation of Information Technologies has been the study of the power and politics of these processes. In this context, the work of Kling $(1978,1980)$ and Markus $(1981,1983)$ has been particularly important. Their pioneering research has not only provided us with a definition of power and politics in the Information Technology context, but also with a theoretical framework that can be applied to new and emerging technologies, such as e-mail.

The major objective of this paper is to build on the work of Kling $(1978,1980)$ and Markus (1983) by extending their power and politics perspective to e-mail. In particular, our research is intended to address the issue of petty tyranny through e-mail. In this context, the major objectives of this paper are:

1. To demonstrate how e-mail features can facilitate mis-use of power by petty tyrants.

2. To describe the effects that petty tyranny through e-mail can have in a work environment.

3. To discuss the theoretical, practical, and ethical implications that the use of e-mail for petty tyranny has for the Information Systems profession.

To frame the discussion, we start with a review of the literature on petty tyranny and its implications to Information Technologies and e-mail (section 1). The review is concluded with a series of assertions (based on Markus, 1983 and Ashforth, 1994) about the use of e-mail for petty tyranny. To demonstrate how these assertions can operate within an organisational context, a case study is presented in section 2 . The case study describes a series of events which took place in a university department. In the case, e-mail was used by the department head to manipulate, control, and coerce employees. The discussion (in section 3) synthesises the analysis by demonstrating that email features made it amenable to political abusive tyrannical uses. In fact, the analysis suggests that it was the abuse of e-mail by the Department Chair that motivated employees to eventually turn against him. The paper concludes with a discussion of the implications from this case to further email research and practice.

\section{THEORETICAL BACKGROUND}

As indicated before, the pioneering work on power and politics in Information Systems was undertaken more than a decade ago. Kling (1980) provided a starting point to this research by identifying six theoretical approaches that can explain resistance to diffusion of Information Technologies: Rational, Structural, Human Relations, Interactionist, Organisational Politics, and Class Politics. Kling indicated that these theoretical approaches differed on a variety of dimensions, 
such as their view of technology, the social setting into which technology is introduced, and the implications for the dynamics of the diffusion process.

Building on Kling's work, Markus (1983) defined three major categories for theories of resistance to diffusion: people-determined, system-determined, and interactionist. The main focus of her paper, however, was on one of the variants of the interactionist theory, i.e., the political. According to this variant of the Interactionist theory, resistance is explained as a product of the "interaction of system design features with the intra-organisational distribution of power, defined either objectively, in terms of horizontal or vertical power dimensions, or subjectively, in terms of symbolism" (p. 432). In other words, this theory predicts that information systems would be resisted by potential users if they cause a re-distribution of power that either conflicts with the organisational structure (objective definition) or with the interests of individuals who are likely to lose power as a result of the implementation (subjective definition). This view of power and politics as determinants of implementation outcome has been elaborated on in further work by the author, including, Markus and Robey, (1983), and Markus and Robey, (1988).

It should be acknowledged that even though Markus has never explicitly applied her political theory of resistance to e-mail, she has recently suggested this direction for future research by concluding her paper on e-mail use (Markus, 1994, p. 523) with the following assertion :

"The adoption, use, and consequences of media use in organisations can be powerfully shaped by social processes such as sponsorship, socialisation, and social control, which require social perspectives to understand them."

The next sections follow the direction proposed by Markus by exploring the ways in which e-mail can be used for manipulation of power within organisations. In particular, the ways in which e-mail can facilitate petty tyranny in the office are explored.

What is a petty tyrant? According to a definition recently proposed by Ashforth $(1994$, p. 1), a petty tyrant is a person who "lords his or her power over others". Based on his own survey research, Ashforth (1994) has identified six characteristics that are typical of petty tyrants: (1) arbitrariness and self aggrandisement, (2) belittling subordinates, (3) lack of consideration, (4) a forcing style of conflict resolution, (5) discouraging initiative, and (6) non-contingent punishment.

As indicated by Ashforth (1994), while the concept of petty tyranny is well understood at the intuitive level, there has been surprisingly little research on the nature of petty tyranny in organisations. The limited research that is available suggests that petty tyranny is determined by individual predispositions and situational facilitators.

The pioneering work on individual predispositions associated with petty tyranny has been conducted by Adorno, Frenkel-Brunswik, Levinson, and Sanford (1950) who described the "authoritarian personality" as one which has the tendency to be dominant toward one's inferiors and submissive toward one's superiors. Thompson (1960), building on Adorno et al's work, described the "bureaucratic individual" who is domineering, impersonal, inflexible and insists on the rights of authority and status. McGregor (1960) has attributed similar characteristics to managers who hold theory $\mathrm{X}$ beliefs, namely, the beliefs that employees are inherently lazy and lacking in motivation and, therefore, need discipline, direction, and control from their superiors. Kipnis (1976) has identified low self confidence as an important antecedent of tyrannical behaviour, while Ray (1981) has singled out "directness" as the tendency to impose one's will on others. Finally, Feather (1971) and Norton (1975) have listed lack of tolerance for ambiguity as a personality trait that would lead superiors to over-control subordinates. 
Topping the list of situational factors that have been associated with petty tyranny are organisational values. Thus, Goffman (1961) and Haney, Banks and Zimbardo (1973) discussed the phenomenon of "institutionalised tyranny", typical of total institutions such as prisons, mental hospitals, and army barracks, where inmates are subjected to extreme forms of authoritarian supervision. Mintsberg (1989) and Hofstede (1978) stressed the effects of mass production on formalised, standardised, and, consequently, often dictatorial management procedures. On the other extreme, Mintsberg (1989) and Kets de Vries (1989) found that "entrepreneurial organisations" were often controlled by individuals who had: (1) strong need for independence and control, (2) distrust of others, and (3) a desire for applause.

Another line of research on situational aspects of petty tyranny considered its micro level antecedents. Within this level two conflicting phenomenal were identified. On one hand, House (1988) and Kipnis (1976) mentioned lack of power as cause of tyrannical behaviour. Individuals who perceive that they are relatively powerless often lord what power they do have. On the other hand, Kipnis (1976) argued that the acquisition and successful use of power tends to corrupt the power holder in several aspects: (1) power becomes an end in itself, (2) the power holder develops and exalted sense of self-worth, (3) power is used increasingly for personal rather than organisational purposes, and (4) the power holder devalues the worth of others.

Finally, stressors may also contribute to petty tyranny. Managers tend to respond to stressors by becoming more directive (Mulder, De Jong, Koppelaar and Verhage, 1986). Under pressure, managers' decision making tends to become more centralised, hasty and arbitrary (Janis, 1982) and as a result they tend to withdraw psychologically from others, treating them more like objects than people (Maslach, 1982). Furthermore, one may justify this stance by blaming others. Thus, Lee and Ashforth (1993) found that managers experiencing emotional exhaustion tended to depersonalise their subordinates and in extreme cases even take perverse pleasure from abusing them.

The purpose of this study is to explore the ways in which e-mail can be used to facilitate petty tyranny in organisations. Based on a case study that is presented in the next section, and along the lines suggested by Markus' (1994) and Ashforth (1994), we make the following assertions:

Assertion 1. - E-mail's features can lend themselves to different types of political mis-use by petty tyrants.

Assertion 2. - Petty tyranny through e-mail can have devastating effects on subordinates.

Assertion 3. - The use of e-mail for petty tyranny has far reaching implications for Information Systems research and practice.

These assertions and their implications to office technology research and practice are explored in the discussion sections of the paper.

\section{CASE STUDY}

\subsection{Data collection}

Data for this study were collected by the authors at a small suburban university (see more details about the university in the following sections). Emphasis during data collection was put on reconstruction of all stages of the implementation process as well as on relevant organisational issues. Textual analysis, interviews, and observations were employed in the study. These were comprehensive and mutually supportive. For example, observations were a source of interview 
questions while the interviews enabled cross-checking of historical details, exploring discrepancies, and probing into personal perceptions. To maximise reliability, both authors were involved in all data analysis activities and were able to reach agreement whenever findings or their interpretation were in dispute.

Textual analysis: A variety of documents were collected, including e-mail promotion materials, training transparencies, and minutes of relevant meetings. Textual analysis also included in-depth study of the organisational chart, hard copy and soft copy of intra-departmental correspondence. A major source of data for this study were about 50 e-mail messages that had been collected by several of the interviewees and were made available to the researchers. Excerpts from the most important of these messages are used to highlight the main events of the case in the following sections of the paper.

Interviews: In-depth interviews with 15 members of the organisation were a major source of data for this study. There were ten interviews with academics in the Department of Accounting. Of these, four were with senior faculty members (Associate Professors and Full Professors), three interviews were with junior faculty (Assistant Professor) and the remaining three interviews with teaching assistants. Two interviews were held with the Department of Accounting secretaries. From top management, the Provost, the personal assistant to the President, and the head of the Information Technology Division which installed e-mail at the Department of Accounting were interviewed. All interviewees had direct or indirect knowledge of the events that are described in the case.

In addition to gathering personal details (such as background, careers, and future plans), interviewees were asked to discuss quality of work life before and during the implementation of email at the Department of Accounting. Although the questions varied from one interview to another, the same topics were covered in all. The taped open-ended interviews, which lasted about ninety minutes each, were transcribed and analysed by the authors.

Observations: Since most interviews took place on the premises of the university, there were additional opportunities for observation.

\subsection{Case history}

UOT (The actual names of organisations, people, and e-mail products are withheld to preserve their anonymity), is a small university, with about 6000 students, 250 academics, and 150 administrative staff. Located in a quiet suburb of a large city, it has not grown substantially since its inception in the early 1950's.

When Mr. Parson announced his resignation as Chair of Accounting in February 1992, accepting a position as Dean of the School of Business in a much larger university, the reverberations were felt in the community within and outside the University. The Department of Accounting is among the largest departments in UOT, attracting over $20 \%$ of the students at the University. The President of UOT, who was to chair the selection committee for the next Department Chair of Accounting, made it clear that only a person with proven superior leadership qualifications could be selected for the job.

After an intense but short selection process, in which ten candidates were interviewed, the job was offered to Mr. Jones, the head of a large accounting firm with many years experience as a part-time honorary professor at the Department of Accounting at UOT. The committee was aware that Mr. Jones had limited experience in research and publications but felt that his leadership skills and extensive links with local industry would more than compensate for his academic shortcomings. The committee was also impressed with his commitment to technological progress. In fact, his announcement that he would "bring technological efficiency to all aspects of managing the 
department" convinced some of the more reluctant members of the committee to agree to his appointment.

One of Professor Jones' first decisions was to make e-mail available to all academic and administrative staff at the Department of Accounting. Since the necessary communication lines were already in place, all that was required was to install communication software and hardware on all personal computers in the department. This was accomplished with the help of the Information Technology Division (ITD) within a few weeks after Professor Jones took office.

Professor Jones' first e-mail message to the members of the department was transmitted on the day the last computer was fitted with the new technology. His message was as follows:

To: All members of the department of Accounting

From: Professor Jones- Chair

By now you must all be aware that we, the Department of Accounting have e-mail!! I am happy to say that it has just been installed on all computers in this department. E-mail will put us at the forefront of communication progress in this university. Other departments will be watching us and, before long, they will probably follow our example. I realise that it might be some time before we all know how to use this new technology. It will require some patience and some work, but master it we will. I wish us all the best of luck on the beginning of this new era in our history.

The first message from Professor Jones was soon followed by several others. In the first of these messages he indicated that he would be meeting with members of the department throughout the week in an attempt to learn how the department operated and how procedures could be improved. In particular, he announced that he will be looking at changing the structure of the department, making it flatter and more decentralised. Before long, another message, outlining the new structure, was transmitted to department members, again, on e-mail. The content of the message was as follows:

To: All members of the department of Accounting

From: Professor Jones- Head

After a lengthy process of consultation with some ten members of this department, I have put together a plan which I would like us to discuss during our department meeting next week.

To prepare you for the meeting, let me just say that I am suggesting a change into a matrix structure. We already have three individuals who are heading our major programs: the BA, the MBA, and the Ph.D. I am suggesting that these positions will be supplemented with three more, the head of corporate accounting, the head of small business accounting, and the head of public sector accounting.

The proposed new positions will support the chair in decisions relating to teaching allocation. In the long term, the fact that we have organised ourselves in terms of these content areas, will also help us consolidate our research and consultancy activities. I am looking forward to hearing your views on these proposals.

Professor Jones opened the first of his monthly department meetings, which was held a few days after the above message was sent, with the announcement that he saw communication on e-mail as a 
major key to efficiency. "It is time", he said, "that this department join the rest of the world in using e-mail as the major media for intra-departmental communication".

He then proceeded to canvass department members' views on his plan to appoint three individuals as heads of the three new groups. Before long, the three most senior professors in each area were voted as the new groups' heads. These included Professor Lee, as head of Corporate Accounting, Professor Cole as head of Small Business Accounting, and Professor Jefferson, as head of Public Sector Accounting

Many faculty in the Department, who were not using e-mail prior to Professor Jones' appointment, actually welcomed his initiative. Attendance in training courses that he organised was high. Even members of the "old guard", who initially thought that e-mail was too difficult for them to master, were enthusiastic participants in the training sessions. Before long, staff members were all using the new technology, joining discussion groups, and browsing through international information databases.

However, it soon became apparent that Professor Jones had other uses for e-mail in mind. The secretaries were the first to become aware of the implications of his "technological policy". Their email screens soon filled up with short messages from Professor Jones, many of which were left the night before, requesting immediate action. Following is an example of one such message.

To: Ms. Carter

From: Professor Jones- Head of Department

It is 5.30pm now and I have just realised that I forgot to give you a letter that needs to be sent to the President tomorrow morning. I will be leaving a hand-written draft of the letter on your desk. Please have it typed and ready for my signature by 9.15 tomorrow morning.

Inability to provide the service that was requested early in the next morning resulted in complaints and reprimands from Professor Jones. During the day, Professor Jones developed a habit, which particularly infuriated the secretaries, of sending them e-mail messages containing requests for cups of coffee to be delivered to him and/or to his frequent industry guests. The "thank you" messages that followed the delivery of the coffee were not welcomed either. As put by the secretaries "a few words, or even a smile would have been much better".

The secretaries, who previously were rarely in the office at $8.30 \mathrm{AM}$, realised that not responding to Professor Jones' e-mail messages by $9.00 \mathrm{AM}$ would be frowned upon. They also discovered that Professor Jones would send "urgent" messages around 2.00 PM in the afternoon to find out if they returned from their lunch break. Failure to respond to those was actually one of the factors that led to the dismissal of Ms. Smith, a young trainee who joined the Department shortly before Professor Jones appointment and was asked to leave a few weeks after he arrived.

As time went by, Professor Jones insistence that e-mail be used by all administrative personnel spilled over to include the academic staff as well. When the secretaries left "pink slips" on his desk from members of the Department who called and wanted him to call back, he routinely responded by e-mail. In one incident he actually exchanged five messages with Professor Carol, a junior member of faculty who wanted to see him, trying to solve a problem, that Professor Jones believed could be solved on e-mail. Following are the messages that were exchanged between the two during this incident.

To: Professor David Jones- Head of Department

From: Professor Michael Carol 
I would appreciate it if you could meet with me today to discuss my teaching allocation for the next semester. I will be in my office today and will be able to see you when you are available.

To: Professor Michael Carol

From: Professor David Jones- Head of Department

Teaching allocations should be discussed with the head of your grouping first. Have you discussed your problem with Professor Lee? Please do. Once you do, please let me know if you still think you need to see me.

To: Professor David Jones- Head of Department

From: Professor Michael Carol

Yes, I did discuss my problem with Professor Lee, but was unable to reach a satisfactory solution. I am aware that you are busy today, but I really need to see you.

To: Professor Michael Carol

From: Professor David Jones- Head of Department

Can you provide me with some details about the meeting? Perhaps I should see Professor Lee before I meet with you. Further details will also make our meeting much more efficient.

To: Professor David Jones- Head of Department

From: Professor Michael Carol

I would have explained the problem here on e-mail, but it is simply too complex and too confidential. I would rather not put it in writing. The problem is also quite urgent and needs to be resolved by today. Can you please see me?

It was by late afternoon that day that Professor Jones agreed to meet with Professor Carol. The meeting was scheduled for several days later, because Professor Jones had to leave for a conference. The whole incident, which Professor Carol later discussed with other members of the department gave a clear signal that e-mail was the preferred way to approach Professor Jones.

Once back from the conference, Professor Jones did meet with Professor Carol. During the meeting Professor Carol shared with Professor Jones a series of problems that he has been experiencing with Professor Lee, the head of the Corporate group. The latest problem was related to teaching allocation within the group. Professor Carol, who was on the first year of his three year contract at the Department and therefore under pressure to publish, objected to Professor Lee's request that he teaches a large compulsory third year course that he had never taught before.

Professor Carol told Professor Jones that other professors within the group, including Professor Lee himself, had taught this course more than once in the past. He insisted that in view of his special situation, he should be allowed to teach the two courses that he already prepared for the first semester, rather than invest a large amount of time, which would take him away from his research, in preparing a new and difficult course. He requested Professor Jones' interference in what he saw as a case in which Professor Lee was abusing his position as head of the group. To support this claim, 
Professor Carol mentioned several other members of the group who opposed Professor Lee and were in agreement with him on this matter.

Professor Jones explained to Professor Carol that the new structure that he introduced would not allow him to overturn Professor Lee's decision. This would send a wrong signal to the members of the department, suggesting that the new group heads were not truly in authority within their groups. He did promise, however, to look into the matter with Professor Lee and come back to Professor Carol with a final decision in a few days.

The following morning, Professor Jones sent the following e-mail message to Professor Lee, inviting him to a meet with him in his office.

To: $\quad$ Professor Michael Lee

From: Professor David Jones

Enclosed please find a message that I just received from Professor Carol. As you can see, Professor Carol is concerned about his assigned teaching allocation for the second semester. I think we should meet to discuss it. Can you please contact my secretary to arrange a time for a meeting?

$<$ To: $\quad$ Professor David Jones- Head of Department

$<$ From: $\quad$ Professor Michael Carol

$<$ I would appreciate it if you could meet with me today to discuss my teaching allocation $<$ for the next semester. I will be in my office today and will be able to see you when you <are available.

During the meeting that was held between the two professors later that day, it became apparent that Professor Lee was not going to change his decision regarding Professor Carol's teaching allocation. The meeting was concluded with Professor Jones' promising to see if he could solve the problem by discussing it again with Professor Carol. A few days later, the following message from Professor Jones was transmitted to the members of the department of Accounting on e-mail:

To: All members of the Department of Accounting

From: Professor Jones - Head of Department

It was brought to my attention by several members of the department that decisions regarding teaching allocations within groups are not necessarily taken in consultation with the faculty members that are involved. In view of the fact that we have to submit our teaching schedule to central administration in three weeks and to maintain the principle of de-centralisation, I suggest that the three discipline groups would meet to discuss teaching allocations for the second semester. The meetings will be chaired by the three heads and will be attended by me. I will provide information about the dates and venues for the meetings once I have the matter cleared with Ms. Carter.

Within a few days, another e-mail message which outlined the dates and venues for the three meetings was transmitted by Professor Jones to the members of the Department. The three meetings were held within a week after the message was transmitted. While there were no particular problems with two of the groups, Professor Lee, the head of corporate accounting did not show up to his 
group meeting. None of the other members of the group was aware of Professor Lee's whereabouts and all attempts by Ms. Carter to locate him failed. After consulting with the other members of the group, Professor Jones announced that in view of Professor Lee's unexplained absence, he (Professor Jones) would chair the meeting. With Professor Jones as chair, the group decided that Professor Lee would teach the third year compulsory subject that he taught in previous years. It was also decided that Professor Carol would teach one of the two subjects that he taught on the first semester and another advanced seminar for a small group of graduate students. Within days after the meeting, Professor Jones sent the Departments' final teaching schedule to central administration.

In the next monthly staff meeting, in early June 1992, Professor Jones announced that those wishing to meet with him should let him know by e-mail what the meeting was to be about. This would ensure that all parties were prepared and the time spent in meetings efficiently used. Professor Jones followed his announcement by regularly informing staff on e-mail of the dates and agendas for meetings. Failure to read one's messages on any particular day could, thus, result in the faculty member not being aware that a meeting was to be held.

In early July 1992, immediately after the final teaching schedule for the second semester was printed and copies distributed to all faculty at UOT, Professor Lee, the head of the Corporate Accounting group and a recently elected Head of the Senate, called the President of UOT, requesting an urgent meeting. In the meeting Professor Lee complained about what he described as a "systematic marginalization of senior faculty members by Professor Jones". He listed several incidents in which senior members, including himself, were not informed in time of upcoming meetings and were consequently unable to attend those meetings. Motions passed in these meetings were then implemented, with little regard for missing faculty members' views and preferences.

The most recent and most disturbing incident which particularly infuriated Professor Lee was a meeting which was held only a week before and to which he, the group head, was not invited. During the meeting his teaching allocation for the next semester was decided in his absence. The decision would have required him to teach an undergraduate course that he did not consider himself qualified to teach even though he had taught it out of necessity in the past. According to Professor Lee, he never received the e-mail message that contained the date and venue for the meeting. Consequently, he scheduled another appointment for that time and was impossible to reach by Ms. Carter when his group meeting was held.

Initially, Professor Lee was unaware that decisions regarding his teaching allocation and the teaching allocation of other members of his group were made in his absence. It was only when he saw the printed and final schedule for the second semester that he realised that Professor Jones, who chaired the meeting, actually overturned his previous decision, assigning one of his courses to a Junior Professor and expecting him, Professor Lee, to teach a large compulsory third year subject that he had not taught for years and did not feel qualified to teach. What infuriated Professor Lee the most was that the decision was made by Professor Jones in spite of the lengthy consultation they had on the matter. Professor Lee was convinced that the overturning of his decision was deliberate and reflected an attempt by Professor Jones to undermine his authority and destroy the unity of his group. He also saw the incident as reflecting a systematic strategy by Professor Jones to victimise and marginalise him and other senior members of the Department.

The President reassured Professor Lee that he would clarify the matters that he raised with Professor Jones. A meeting between the two followed a few days later. Even though the meeting took place behind closed doors, the rumour was that it developed into an ugly confrontation, culminating with Professor Jones' threat to resign. A letter of resignation from Professor Jones was submitted to the President the next day. By the end of the week, a formal announcement that the 
position of Chair of Accounting had been advertised was made by the President during a Senate meeting. Professor Lee was appointed as the interim Department Chair.

\section{DISCUSSION}

Technically, the diffusion and implementation of e-mail at the Department of Accounting was a great success. Within a relatively short period of time all members of the Department, including the "old guard" who were initially wary of the new technology, were using e-mail extensively. Thanks to Professor Jones' leadership, e-mail became the communication medium of choice, almost completely replacing all other communication technologies.

And yet what makes the case so interesting is that the technical success of e-mail was accompanied by unexpected political side effects. How can these political side effects be explained? Is there something that is inherent to e-mail which makes it particularly amenable to abusive political use by mangers? Was it a coincidence that by the end of the case study two individuals (the office trainee, and Professor Jones) were asked to leave the Department?

Earlier in the paper, at the end of the literature review, we proposed a series of assertions about the relationship between e-mail and petty tyranny. In the following sections we go back to these assertions and see to what extent they have been supported by the data in the case.

Assertion 1. - E-mail's features can lend themselves to different types of political mis-use by petty tyrants.

What features of e-mail were used politically in the case?

A recent publication by Romm and Pliskin (1995) outlines five distinct features of e-mail that can lend themselves to political usages. Applied to the case study in the previous sections, these features were manifested in the following ways:

Speed - Romm and Pliskin (1995) define this feature of e-mail as the fact that messages transmitted on e-mail can reach their destination, whether it is in the other room or the other side of the globe, in a relatively short period of time. They maintain that this feature can have significant political implications, particularly when communication with large groups of people is involved. In our case, the speed of e-mail made it possible for Professor Jones to convene meetings at short notice, including the one which Professor Lee was unaware of. The speed of e-mail was also the major feature which allowed Professor Jones to use e-mail to control his secretaries comings and goings.

Multiple Addressability - Romm and Pliskin (1995) define this feature as the capacity to send an email message instantaneously and simultaneously to a large group of individuals within and outside an organisation. This feature too is considered of utmost political importance. In our case the multiple Addressability feature lent itself to several political uses. First, it enabled Professor Lee's secretary to organise meetings on his behalf at a relatively short notice, keeping all faculty members hooked to their computers in fear that they might miss an important message. As a result, this feature endowed Professor Jones with enormous power as the centre of most communication activities in the Department. 
Recordability - Romm and Pliskin (1995) define this feature of e-mail as the capacity to store e-mail messages in a data base for transmission or processing at a later point in time. This feature allows political actors to collect e-mail messages (that may not have political significance when they are received) for future use when circumstances have changed to make the information politically useful. In our case, the recordability feature of e-mail was utilised by Professor Jones in his "campaign of terror" against the secretaries. Being able to record the exact time in which they responded to his messages (particularly the ones left late the previous night) made it possible for him to keep accurate track of their comings and goings. The e-mail "evidence" then allowed him to reprimand and even fire one of the secretaries for failure to meet his demands.

Processing - Romm and Pliskin (1995) define this feature of e-mail as the capacity to modify the content and structure of e-mail messages by the receiver prior to transmitting them to others. This feature allows political actors to add comments to data previously collected, thus turning neutral messages into highly politically explosive ones. In our case, the processing feature of e-mail was utilised when Professor Jones sent a copy of Professor Carol's message to Professor Lee, with an attachment that indicated that he took the matter seriously and was going to intervene on Professor Carol's behalf.

Routing - Romm and Pliskin (1995) define this feature of e-mail as the capacity of senders to transmit messages to selected groups of addressees whose names may or may not appear as receivers of copies. This feature allows senders to transmit slightly (but significantly) modified messages to individuals who supposedly receive the same message. It can also allow senders to re-transmit messages to individuals that the original sender did not wish to share the message with. These uses obviously have strong political implications. In our case, the routing feature of e-mail may have been exploited when Professor Lee was the only person in the Department not to receive a copy of the invitation to the group meeting. Our interviews with the different members of the Department failed to establish what actually happened to the message that Professor Jones claimed he sent to Professor Lee and Professor Lee claimed he never received. In theory, three explanations are possible. One is that Professor Lee lied about not receiving the message. Another explanation is that he deleted the message by mistake, without actually reading it. Finally, and most plausibly, considering the circumstances of the case, there is the possibility that the message was, indeed, never sent, reflecting a deliberate attempt by Professor Jones to "route" the message, whereby, excluding Professor Lee from the decision making process of his group.

Assertion 2. - Petty tyranny through e-mail can have devastating effects on subordinates.

What effects did the use of e-mail by Professor Jones have on his subordinates?

From the case we learn of several effects that Professor Jones abuse of e-mail had on his subordinates. First, Professor Jones used e-mail to keep a record of employees' comings and goings, particularly his secretaries. As a result of this practice the secretaries did improve their punctuality and productivity. However, this improvement was achieved at a high price. One of the secretaries, who was unable to adjust to the new work environment, was fired. The others worked under increased stress and were highly frustrated and resentful of their new boss.

Another abusive use of e-mail by Professor Jones involved the discouragement (through e-mail) of employees from using any other form of communication with him. As demonstrated by the incident with Professor Carol, e-mail was used by Professor Jones to create a "psychological distance" 
between himself and his subordinates. This ploy did not only annoy and frustrate employees but also caused a reduction in productivity as employees were forced to waste enormous amount of time on futile (but necessary) attempts to establish face to face contact with Professor Jones.

Finally, and most importantly, Professor Jones used e-mail in order to selectively screen information, making some of it available only to individuals that he wanted to share it with. Whether Professor Jones did or did not send the invitation to Professor Lee, it is clear from the case that he made full political use of the fact that Professor Lee was not in the room when the meeting was held. In the short term, this manipulation resulted in Professor Lee being out-manoeuvred, and if it were not for his own counter-attack, being forced to teach a course that he felt unqualified to teach. It was only Professor Lee's political clout in UOT that made it possible for him to turn the table on Professor Jones and eventually use the incident to force Professor Jones out of the Department.

Going back to the literature on petty tyrants, there is no question that Professor Jones uses of email in this case and the devastating effects that these uses had on his subordinates are examples of petty tyranny. From the research on petty tyranny we learn that tyrannical behaviour by managers tends to have the following effects on subordinates(Ashforth, 1994):

Petty tyranny tends to be associated with low leadership endorsement. In our case, and perhaps because he was a new Chair, Professor Jones was definitely not endorsed by the majority of the members of his department, which led to his eventual dismissal.

Petty tyranny tends to foster employees' frustration, stress, and reactance. In our case, as indicated in the previous sections, Professor Jones' manipulations of e-mail have resulted in employees' frustration, stress, and at least in Professor Lee's case, reactance.

Petty tyranny tends to lead to employees' helplessness and work alienation. In our case, perhaps because Professor Jones was not around long enough, helplessness and alienation have not developed. Given more time, and considering Professor Jones' leadership style, it is most likely that such phenomena would have developed.

Petty tyranny tends to undermine employees' self esteem and consequently decrease performance. As indicated in the previous sections, our case contains several examples of the negative effects of Professor Jones' behaviour on employees' self esteem and consequently their performance.

Petty tyranny may undermine social unit cohesiveness. In our case, the conflict that erupted between Professor Lee and Professor Carol has been indirectly fuelled by Professor Jones. Under the guise of "the arbitrator", he managed to pit the two professors against each other, and indirectly undermine the unity of their group.

Assertion 3. - The use of e-mail for petty tyranny has far reaching implications for Information Systems research and practice.

What are the theoretical and practical implications from this research?

The first and most important theoretical implication is that e-mail should be considered a technology with strong political potency, possibly stronger than any other communication technology that is currently utilised in organisations. In this paper we have mostly discussed the potential that e-mail has for negative uses, i.e., uses that conflict with employees' welfare and as a consequence with the organisational long term productivity. There are, however, quite a few other, potentially beneficial and yet political uses of e-mail. Among these the most important are employees' individual political empowerment and coalition building. Sproull and Kiesler (1991) in a landmark research on e-mail's social effect in organisations listed the democratising effect of e-mail as one of 
its most socially promising features, asserting that through e-mail employees at the bottom of the organisation can gain immediate and unfiltered access to top management.

This study has described one incident in which e-mail was utilised for mostly negative political purposes. Based on one case, which occurred in a given organisational and cultural context, this paper is obviously unable to chart the range of political activities, negative or positive, that e-mail can lend itself to. It remains for future research to establish the boundaries of the political activities possible on e-mail across different industries and different cultural backgrounds. It also remains for future research to establish the effect of the merging of technologies (e-mail with Fax, e-mail with teleconferencing) on the political uses of office technologies.

Another important issue that is raised by this research is that e-mail, by virtue of its political potency can increase tensions between conflicting factions in an organisation. It should be noted that the data that has been presented here cannot conclusively prove that e-mail caused the events in the case. The tensions between Professor Jones, the new Department Chair, and the Department "old guard", represented by Professor Lee, may have existed before e-mail was introduced and abused. It is plausible to assume, however, that e-mail's presence brought the tensions that were already in existence in the Department to a head, with devastating results to all concerned.

The fact that e-mail's effect cannot be "proven" as the one factor explaining the events in the case is supported by recent theoretical assertions by Soh and Markus (1995) and by Robey (1995). As indicated by Soh and Markus (1995) cause and effect relationships are often impossible to demonstrate in IS research. Theories of process which focus on necessary conditions that bring about a given result are therefore preferable to theories of variance which focus on sufficient conditions that may or may not bring about a given result. A similar point is raised by Robey (1995, p. 61) who indicates that "Efforts to encompass contradiction in theory reveal the difficulty and futility of making simple predictions about the organisational consequences of information technology". Following this assertion, Robey advocates the adoption of less simplistic theories that put less emphasis on significant empirical associations between variables and more emphasis on plausible explanations of observed phenomena.

Finally, this study raises a series of intriguing ethical dilemmas for researchers and practitioners interested in the organisational implications of office technology. As indicated in the case, e-mail can be used by management to control and abuse employees. In extreme cases, such as the one described here, e-mail can be exploited to significantly affect employees' well being. What should be the role of IS practitioners in such cases? Should IS practitioners advise managers against the use of e-mail for abusive purposes? Should such advice be made part of managers' and employees' training on how to use e-mail? Should IS professionals interfere when e-mail is used for negative purposes? It remains for the IS profession and society as a whole to debate and perhaps legislate the use and abuse of email in organisations.

\section{REFERENCES}

Adorno, T. W., Frenkel-Brunswik, E, Levinson, D. J. and Sanford, R. N. (1950) The Authoritarian Personality, Harper and Row, New York.

Ashforth, B. E. (1994) Petty Tyranny in Organizations, Human Relations, 47, 7, 755-78.

Culnan, M. J. and Markus, M. L., (1987), Information Technologies: Electronic Media and Interorganizational Communication, In F. M. Jablin, L. L. Putnam, K. H. Roberts, and L. W. Porter (Eds.), Handbook of Organisational Communication: An Interdisciplinary Perspective, Sage Publications, Newbury Park, CA., pp. 420-43. 
Eveland, J. D. and Bikson, T. K., (1988), Work Group Structures and Computer Support: A Field Experiment, ACM Transactions on Office Information Systems, 6, 4, 354-79.

Feather, N. T. (1971) Value Differences in Relation to Ethnocentrism, Intolerance of Ambiguity and Dogmatism, Personality, 2, 349-66.

Goffman, E. (1961) Asylums: Essays on the Social Situation of Mental Patients and Other Inmates, Anchor Books, New York.

Haney, C., Banks, C. and Zimbardo, P. (1973) Interpersonal Dynamics in a Simulated Prison, International Journal of Criminology and Penology, 1, 69-97.

Hofstede, G. (1978) The Poverty of Management Control Philosophy", Academy of Management Review, 3, 450-61.

House, R. J. (1988) Power and Personality in Complex Organizations, in B. M. Staw and L. I. Cummings (Eds.) Research in Organizational Behaviour (Vol. 10). Greenwich, CT: JAI Press, pp. 305-57.

Janis, I. L. (1982) Decision Making Under Stress, in L. Goldberger and S. Breznitz (Eds.), Handbook of Stress: Theoretical and Clinical Aspects. New York, Free Press, pp. 69-87.

Kets de Vries, M. F. R. (1989) Prisoners of Leadership. New York, Wiley.

Kipnis, D. (1976) The Power holders. Chicago, University of Chicago Press.

Kling, R. (1978) Automated Welfare Client Tracking and Service Integration: The Political Economy of Computing, Communication of the ACM (June), 484-93.

Kling, R. (1980) Social Analysis of Computing: Theoretical Perspectives in Recent Empirical Research, Comput. Surv, 12, 1, 61-110.

Lee, R. T., and Ashforth, B. E. (1993) A Longitudinal Study of Burnout Among Supervisors and Managers: Comparisons Between Leiter and Maslach (1988) and Golembiewski et al (1986) models, Organizational Behaviour and Human Decision Processes, 54, 369-98.

Markus, M. L., (1981) Implementation Politics - Top Management Support and IS Involvement, Systems, Objectives, Solutions, pp. 203-15.

Markus, M. L. (1983) Power, Politics, and MIS Implementation, Communications of the ACM, 26, 6, 430-44.

Markus, M. L., (1994), Electronic Mail as a Medium of Managerial Choice, Organization Science, $5,4,502-27$.

Markus, M. L. and Robey, D., (1983), The Organizational Validity of Management Information Systems, Human Relations, 36, 3, 203-26.

Markus, M. L. and Robey, D. (1988) Informational Technology and Organizational Change: Causal Structure in Theory and Research, Management Science, 34, 5 (May), 583-94.

Maslach, C. (1982) Burnout: The Cost of Caring, Prentice Hall, New York.

McGregor, D.(1960) The Human Side of Enterprise. McGraw Hill, New York.

Mintzberg, H. (1989) Mintzberg on Management: Inside Our Strange World of Organizations. Free Press, New York.

Mulder, M. De Jong, R. D., Koppelaar, L., and Verhage, J. (1986) Power, Situation, and Leaders' Effectiveness: An Organizational Field Study, Journal of Applied Psychology, 71, 566-70.

Norton, R. W. (1975) Measurement of Ambiguity Tolerance. Journal of Personality Assessment, 39, 607-19.

Pliskin, N., (1989), Interacting with Electronic Mail can be a Dream or a Nightmare: a User's Point of View, Interacting with Computers, 1, 3, 259-72.

Pliskin, N., Ball, L. D., and Curley, K. F., (1989), Impediments to Proliferation of Electronic Mail: A Study from the Users' Perspective, Human Systems Management, 8, 3, 233-41. 
Pliskin, N. and Romm, T., (1990), Design of Charging Mechanisms According to the Interaction between Information Technology Type and Diffusion Life cycle Phase, Database, 21, 3, 34-40.

Pliskin, N., Romm, T., Lee, A. S., and Weber, Y., (1993), Presumed versus Actual Organizational Culture: Managerial Implications for Implementation of Information Systems, The Computer Journal, 36, 2, 1-10.

Ray, J. J. (1981) Authoritarianism, Dominance, and Assertiveness. Journal of Personality Assessment, 45, 390-97.

Robey, D. (1995) , Theories that Explain Contradiction: Accounting for the Contradictory Organizational Consequences of Information Technology, in Proceedings of the Sixth International Conference on Information Systems (ed. J. I. DeGross, G. Ariav, C. Beath, R. Hoyer, and C. Kemerer), Amsterdam.

Romm, C. T. and Pliskin, N. (1995) Virtual Politicking: Toward a Theory of E-mail Use for Political Purposes Within and Between Organisations", forthcoming in The Handbook of Administrative Communication (Eds. J. L. Garnett and A. Kouzmin) Marcel Dekker, New York.

Romm, T., Pliskin, N., Weber, Y., and Lee, A. S., (1991) Identifying Organizational Culture Clash in MIS Implementation: When is it Worth the Effort?, Information \& Management, 21, 99-109.

Sproull, R., and Kiesler, S. (1991), (eds.), Connections: New Ways of Working in the Network, MIT Press, Cambridge, MA.

Soh, C. and Markus, M. L. (1995) How IT Creates Business Value, in Proceedings of the Sixth International Conference on Information Systems (ed. J. I. DeGross, G. Ariav, C. Beath, R. Hoyer, and C. Kemerer), Amsterdam.

Thompson, V. A. (1960) Modern Organization. Alfred A. Knopt, New York.

\section{BIOGRAPHIES}

Dr Celia Romm is an Associate Professor and Director of the HRM/OB specialisation at the Department of Management, the University of Wollongong, Australia. She received her Ph.D. in Applied Psychology from the University of Toronto, Canada. She has been a lecturer, consultant, and visiting scholar in Israel, Japan, Germany, Canada, and Australia. Her research interests lie in the areas of organisational power and politics, human resources decision support systems, the impact of communication technologies on organisations, and marketing of higher education. Dr. Romm published in such journals as Human Relations, Organisation Studies, Comparative Economic Studies, Information and Management, The Computer Journal, Database, The Journal of Information Systems Management, The Australian Journal of Information Systems, The Asia Pacific Journal of Human Resources, Higher Education, European Journal of Education, Interchange, and Management Education and Development.

Dr. Nava Pliskin is an Associate Professor at the Department of Industrial Engineering and Management at the Ben-Gurion University of the Negev, Israel. She holds a Ph.D. degree from Harvard University. Her research interests lie in the areas of management information technologies and the organisational implications of Information Systems' implementation (e.g. Power, Culture etc.). Dr. Pliskin published in such journals as Information and Management, Database, Human Systems Management, Information and Software Technology, Interacting with Computers, IEEE Transactions on Engineering Management, and the Journal of Information Systems Management. 